\title{
Study of somatic, motor and functional effects of practicing initiation programs in water gymnastics and swimming by students of physical education and sports
}

\author{
Badau Adela \\ Department of Physical Education, Faculty of Medicine, \\ University of Medicine and Pharmacy of Targu Mures, Romania
}

\begin{abstract}
Purpose:

The implementing within the academic physical education and sports curricula of a new discipline such as water gymnastics falls within the current trends of curriculum modernization. Purpose: The purpose of the study aims at evaluating the effects of driving, exercise-induced functional and somatic programs initiation of the gymnasts in the water compared to the effects specific to the initiation swimming.

Material: $\quad$ research duration: two semesters / 14 practical courses. In the first semester the water gymnastics initiation program was implemented and in the second semester the swimming initiation program was implemented. Research Tests: Pretest in the first practical lesson of each semester and posttest in the last lesson of each semester. Participants: 34 male students, specializing in physical education and sport. Somatic, motor and functional assessment: weight, height, BMI, basal metabolism; H2O\%, fat\%, 2km UKK test, VO2max, fitness index. Statistical processing SPPS 20: arithmetic mean, standard deviation, t-test, probability threshold.

Results: $\quad$ improvements relevant to the aqua-gymnastics group: VO2max $7.07 \mathrm{ml} / \mathrm{min} / \mathrm{kg}$; Test duration $2 \mathrm{~km}$ UKK 1.049 minutes; BMI 0.255; and the group of swimming VO2max $0.43 \mathrm{ml} / \mathrm{min} / \mathrm{kg}$; Duration $2 \mathrm{~km}$ UKK $0.44 \mathrm{minutes}$; BMI 0.139 .

Conclusions: $\quad$ effects on the functional motor and exercise-induced somatic programs initiation water gymnastics are significantly superior to those of initiation in swimming. We recommend conducting further studies to assess the effects of gymnastics on water through differentiated programs on levels of physical training, age, and the use of various sporting materials.

Keywords: $\quad$ aqua-gymnastics, swimming, fitness index, body fat percentage, VO2max, caloric intake.
\end{abstract}

\section{Introduction}

Increasing the competitiveness of academic physical education (PE) can be achieved by implementing within the curricula of some innovative disciplines allowing the acquisition of additional professional knowledge and skills in accordance with the modern requirements and the expansion of practicing forms of physical activities [1].

The place and the role of physical education in the context of high quality integrated education are clearly defined and aimed at maximizing the human potential imposed by the dynamics of modern society [2].

The diversification of indoor aquatic activities was possible owing to the influences of modern technology that created a series of materials and installations adapted to both aquatic environment with the targeted objectives and the peculiarities of sport practitioners. Introducing water gymnastics into university curriculum to students from physical education specialization contributes to expanding and increasing the attractiveness of aquatic activities. By the curricular extension of aquatic activities we aimed at training new motor skills and teaching competences to students from physical education and sports.

Education should be directed to the needs of the knowledge society to the problems that emerge from the current modern context that applies in the future [3].

The human motor behavior appears as a complex chain of movements, attitudes, or postures whereby a man adapts to different ever changing environmental conditions [4].

The topicality of our research consists of comparing the functional and somatic adaptive effects induced by

(c) Badau Adela, 2017

doi:10.15561/20755279.2017.0402 two types of activities carried out in aquatic environment: water gymnastics and swimming, addressed to students from the physical education and sports specialization, comprising modules of 14 practical lessons. The assessment was made on the ground since recent studies have shown that $\mathrm{VO}_{2 \max }$ test in water is a complex and difficult process that involves risks [5-9].

We mention that within the curriculum of the Physical Education and Sports Specialization Program of the University of Medicine and Pharmacy of Targu Mures, there are two aquatic disciplines: swimming and water gymnastics, each with 7 theoretical courses and 14 practical lessons which are conducted in two consecutive semesters in the first year of study.

The possibilities of the aquatic environment can contribute to the active level of physical activity as a key contribution to health and aging that derives from its special features, working at functional and aesthetic levels [10].

Regarding the efficiency of the swimming methodology to physical education students, Dragan Toskić and colleagues, (2013) [11] concludes that the study has shown that some other methods and forms of organization can provide better results than those achieved within the current method of work, since, as mentioned at the beginning, the role of the university, faculty and teacher is to encourage students and enable them to realize their abilities so that they can be awarded the highest grades possible.

In 2008 Statkevicienè B. and collab., [12] conducted a study that targeted the level of performance in different swimming techniques correlated with anthropometric indices for young people aged 18 (years). 
The aquatic environment presents physical properties that facilitate the diversification of movements, among which buoyancy allows three-dimensional movements and positions that can not be reproduced on the ground, stimulating the sensory area of the central nervous system. This force facilitates the possibility of multiple combinations of movement in various plans [13].

Water gymnastics is an optimal combination of: basic and aerobic gym exercises, fitness, stretching and hydromassage, aiming mainly at improving the harmonious physical development, the posture and the motor and functional ability. Water gymnastics is an innovative activity of motor education technology, adapting to specific age and training specificities as well as to individual and group preferences, contributing to the optimal change in behaviors and physical capabilities.

Specialists in the field of motor activities consider that the innovative and attractive use of environments to carry out the activities, of the modern methods and technologies will contribute to the curricular optimization and the skills improvement of the future specialists $[1,10,14]$.

\section{Purpose and hypothesis}

Formulating the hypothesis we started from the assumption that initiation in the exercise of water gymnastics programs has superior functional and somatic beneficial effects compared to initiation in swimming practice, during 14 practical lessons per semester, to students in the first year of study from the specialization of physical education and sport.

The study aims to determine the functional and somatic changes induced by practicing two types of aquatic physical activities: water gymnastics and swimming to students from the physical and sports education specialization, first year of study. The functional changes targeted: the vital capacity by the indicator $\mathrm{VO}_{2 \max }$ and the fitness index which stands for the motor ability level; the somatic changes: BMI, the body fat and water percentage in relation to the differentiated caloric intake of the two physical aquatic activities- gymnastics in water and swimming.

\section{Material and methods}

Participants: The research included a number of 34 male students from Physical Education and Sports, $1^{\text {st }}$ year, from the University of Medicine and Pharmacy in Tirgu Mures. The research subjects did not practice swimming as a performance sport, their average age $22.60 \pm 1.95$ years, average height $1.80 \pm .07$ meters. All participants in this study were volunteers.

Procedure: The research was conducted during the academic year 2015-2016 at Salus Spa per Aqua within Targu Mures University of Medicine and Pharmacy, which is equipped with a swimming pool $1.3-2.5 \mathrm{~m}$ deep, $25 \mathrm{~m}$ long, 6 Standard lanes. The swimming pool's design allows practicing gymnastics in water over a third of the pool's length where the depth is $1.3 \mathrm{~m}$, and then it increases progressively.

The research was conducted during two semesters, in the first semester the students were initiated and evaluated in water gymnastics discipline, and in the second semester in swimming discipline - the initiation course. Each discipline included a total of 14 practical lessons of 90 minute duration and 7 theoretical courses.

In the study framework two tests were carried out, as follows:

- In water gymnastics discipline, the pre-test was applied in the first week of semester I, and the posttest in the 14th week of the semester;

In swimming discipline, the pre-test was applied in the first week of the second semester, and the posttest in the 14th week of the semester.

- The operational water gymnastics programs have been differentiated all along the first semester on three value modules according to the degree of difficulty, the intensity and the complexity of the systems: beginners, intermediates and advanced ones.

- beginner level - in a four-lesson period free, simple or complex exercises were performed, aiming to familiarize with the aquatic environment and to learn the specific gymnastics motor skills; the programs' choreography was simple;

intermediate level- in a six-lesson period exercises with a higher complexity were included through the use of sports objects: palm, dumbbells of $1 \mathrm{~kg}$, a pull/ push plate, sandbags attached to the ankles; midlevel choreography;

advanced level- in a four-lesson period exercises with a degree of difficulty, the acting intensity and complexity were higher and the choreography more complex, using materials and equipment such as: plates, dumbbells weight varying between $2 \mathrm{~kg}$, palmars of greater surface, steppers etc.; elaborate choreography.

The curriculum content of the swimming discipline, conducted during the second semester, included the classic program of 12 lessons of initiation in the technical execution of swimming procedures: crawl, backstroke and breaststroke.

Tests applied: Before the start of the motor test, the anthropometric measurement of the subjects, using the magnetic impedance scale, aimed at the following parameters: height $(\mathrm{cm})$, weight $(\mathrm{kg})$, percentage of fat $(\%)$ and percentage of water $(\%)$. In order to evaluate the functional capacity it was applied the $2 \mathrm{~km}$ UKK test, designed by the Finnish physician Dr. Kenneth Cooper [16], a testing component of Eurofit adult test battery, which consists of $2 \mathrm{~km}$ brisk walking in the open air or indoors on the treadmill with a platform's tilt index to " 0 ". We opted for the $2 \mathrm{~km}$ UKK test because it responds to the study's objective of measuring overall functional capacity and can be applied to both aquatic activities that suppose different body positions and different types of effort. The required parameters to evaluate the $2 \mathrm{~km}$ UKK walking test were: IMC, age, height, heart rate, and test performing duration. It starts with a slight warming up, the emphasis is on the lower limbs, and then it takes a regular cadence, about 200 meters, until it sets an individually acceptable 
pace. Once the test is started, the time taken to cover the $2 \mathrm{~km}$ is counted and the heart rate value is recorded at the end of the test.

Based on the results of the $2 \mathrm{~km}$ UKK test, the fitness index (IF) was calculated according to the formula:

$$
\begin{gathered}
I F(\text { men })=420-(11.6 \min +0.2 \mathrm{sec}+0.56 \mathrm{HR}+2.6 \\
\text { BMI })+0.2 \text { years }
\end{gathered}
$$

Where: HR - heart rate at the end of the test within one minute; Years - the age of subjects; BMI-weight $(\mathrm{kg}) /$ height $(\mathrm{m})$ squared. Interpretation of UKK $2 \mathrm{~K}$ test results: Depending on the correlation with UKK Institute scores, it has five levels of appreciation: $<70$ well below the average; $70-89$ somewhat below average; $90-110$ average; 110 - 130 something above average; > 130 well above average.

The maximum quantity of oxygen measured in $\mathrm{ml} /$ $\mathrm{min} / \mathrm{kg}\left(\mathrm{VO}_{2 \max }\right.$ included the following parameters: age, BMI, the time obtained in $2 \mathrm{~km}$ UKK walking test (min.) and the heart rate at the end of the test, it was calculated by the formula:

$$
\begin{aligned}
V O_{2 \max }(\text { men })=184.9 & -4.65 \text { time }- \text { HR } 0.22-0.26 \text { years } \\
& -1.05 \text { BMI }
\end{aligned}
$$

Interpretation of $\mathrm{VO}_{2 \max }$ for 20-29 years on assessment levels is: decreased $<25$ - Insufficient; $25-33$ - Average; 34 - 42 - Good; 43 - 52 - Excellent. Where: HR = HR/ HRmax X 100.

Basal metabolism (BM) reflected by the caloric requirement of the subject's weight and age, according to the following formula:

$$
\begin{gathered}
B M=66.47+13.75 X \text { Weigt } X 5 X(100 X H)-6.76 X \\
\text { years }
\end{gathered}
$$

\section{Statistical processing}

For statistical calculations, we used SPSS 20.0 for Windows. The statistical analysis included determination of the following: the arithmetic mean (x) and the standard deviation (SD) (Table 1). The calculation of statistical significance between the pre-test and the post-test on the ground targeted, apart from the difference of the arithmetic means of SD, the t-test student too, the significance threshold $\mathrm{p}$, for $\mathrm{p}<.05$ (Table 2 ).

\section{Results}

As a result of the research done by calculating the arithmetic mean difference between the two tests, there were significant differences in values after conducting water gymnastics lessons compared to those provided in the course of practical classes from the swimming discipline, the basic course as follows (Table 1):

- Body weight, after practicing gymnastics in water, decreased by $0.814 \mathrm{~kg}$ compared to $0.483 \mathrm{~kg}$ after swimming lessons, the subjects having a normal weight in both tests;

- The time obtained to run the $2 \mathrm{~km}$ UKK test on the treadmill, declined by 1049 minutes in water gymnastics group and by 0.44 minutes in swimming group;

The heart rate (HR) recorded at the end of the test, showed an improvement of 8.733 beats / minute for water gymnastics and only 0.5 beats per minute for swimming;

Concerning \% RH, which is an important indicator to determine the work stress, it decreased by $4.508 \%$ in water gymnastics and by only $0.258 \%$ in swimming, which is relevant for a more efficient adaptation to effort for water gymnastics compared to swimming;

- The distance resulting from the $2 \mathrm{~km}$ distance transformation, specific to the UKK test, and the test time, reported at $60 \mathrm{~min}$, increased by 0.435 in water gymnastics compared to $0.013 \mathrm{~km}$ in swimming;

BMI - all the subjects in both tests were within a normal weight $>25$, and after the research experiment there was a decrease of 0.255 in water gymnastics group and of 0.139 in swimming group;

The fitness index (IF) recorded a significant improvement of 17.725 units in water gymnastics group and only 1.075 units in swimming group. The difference is justified by the required effort in water gymnastics activity during which sports teaching materials were used; they require superior/higher efforts for their handling compared to the effort needed at the initiation swimming lessons. In initial testing done at the beginning of the first semester, subjects were within an average fitness level and at the final testing they ascended to something above average level of appreciation. During the holiday period between semesters IF level fell to average which was maintained during the second semester, when the practical works of swimming discipline took place;

The vital capacity through the indicator $\mathrm{VO}_{2 \max }$ recorded a significant improvement after practising water gymnastics: $7.07 \mathrm{ml} / \mathrm{min} / \mathrm{kg}$, in the first semester of the academic year, starting from the score well to initial testing and reaching the score excellent in the final testing. This improvement of the vital capacity achieved in the first semester was also reflected on the initial test in the swimming activity performed in the second semester, making it possible for subjects to fall within an excellent level in both tests, with a difference between them of $0.43 \mathrm{ml} / \mathrm{min}$ / kg;

- The basal metabolism (BM) by the calories consumption indicator was improved by 11.092 calories after practicing gymnastics in water and by 6646 cal. in swimming, which means a body adaptation to the effort specific to both aquatic activities;

The body water quantity whose value was calculated by a standard electronic scale recorded a decreased retention of 0.134 liters after exercise in water and of 0173 liters after swimming;

The body fat was reduced by $0.337 \%$ after practicing gymnastics in water and by $0.186 \%$ after swimming. The analysis of the differences between the tests 
Table 1. Descriptive statistics for the results of the tests of somatic and functional for aqua-gymnastics group and swimming group, pretest and post-test

\begin{tabular}{|c|c|c|c|}
\hline Items & Tests & $\begin{array}{l}\text { Aqua - gymnastics } \\
X \pm S D\end{array}$ & $\begin{array}{l}\text { Swimming } \\
X \pm S D\end{array}$ \\
\hline \multirow{2}{*}{ Weight (kg) } & Pretest & $78.62 \pm 7.93$ & $78.18 \pm 7.49$ \\
\hline & Posttest & $77.81+7.48$ & $77.70 \pm 7.04$ \\
\hline \multirow{2}{*}{ Duration 2km UKK (min.) } & Pretest & $16.13 \pm 1.00$ & $15.91 \pm .75$ \\
\hline & Posttest & $15.08 \pm .66$ & $15.47 \pm .76$ \\
\hline \multirow{2}{*}{ HR (pulse / min) } & Pretest & $126.26 \pm 10.74$ & $124.26 \pm 7.67$ \\
\hline & Posttest & $117.53 \pm 6.59$ & $123.76 \pm 7.37$ \\
\hline \multirow{2}{*}{$H R(\%)$} & Pretest & $65.18 \pm 5.52$ & $64.16 \pm 3.98$ \\
\hline & Posttest & $60.67 \pm 3.40$ & $63.90 \pm 3.82$ \\
\hline \multirow{2}{*}{ Distance 2km UKK (km) } & Pretest & $7.46 \pm .47$ & $7.76 \pm .44$ \\
\hline & Posttest & $7.97 \pm .35$ & $7.77 \pm .38$ \\
\hline \multirow{2}{*}{ BMI } & Pretest & $24.07 \pm 2.13$ & $23.94 \pm 2.03$ \\
\hline & Posttest & $23.81 \pm 1.87$ & $23.80 \pm 2.00$ \\
\hline \multirow{2}{*}{ Fitness level } & Pretest & $103.87+16.34$ & $112.50 \pm 14.31$ \\
\hline & Posttest & $121.59 \pm 11.40$ & $113.58 \pm 13.33$ \\
\hline \multirow{2}{*}{$\mathrm{VO}_{2 \max }(\mathrm{ml} / \mathrm{min} / \mathrm{kg})$} & Pretest & $50.93 \pm 6.74$ & $54.40 \pm 5.92$ \\
\hline & Posttest & $58.00 \pm 4.77$ & $54.83+5.54$ \\
\hline \multirow{2}{*}{ BM (Calories) } & Pretest & $1898.59 \pm 130.62$ & $1892.09 \pm 125.58$ \\
\hline & Posttest & $1887.50 \pm 127.12$ & $1885.45 \pm 118.91$ \\
\hline \multirow{2}{*}{$\% \mathrm{H}_{2} \mathrm{O}(\%)$} & Pretest & $50.98 \pm 4.22$ & $50.83 \pm 4.21$ \\
\hline & Posttest & $51.12 \pm 3.85$ & $51.00 \pm 4.20$ \\
\hline \multirow{2}{*}{$\%$ Fat $(\%)$} & Pretest & $25.52 \pm 7.86$ & $25.48+7.87$ \\
\hline & Posttest & $25.18+6.58$ & $25.30 \pm 7.37$ \\
\hline
\end{tabular}

$X$ - mean arithmetic; SD - standard deviation.

Table 2. Descriptive statistics for the results of the tests of somatic and functional for aqua-gymnastics and swimming groups, between pretest and post-test

\begin{tabular}{|c|c|c|c|c|c|c|c|}
\hline \multirow{2}{*}{ Items } & \multirow{2}{*}{ Tests } & \multicolumn{3}{|c|}{ Aqua - gymnastics } & \multicolumn{3}{|l|}{ Swimming } \\
\hline & & $X \pm S D$ & $\mathbf{T}$ & $\mathbf{P}$ & $X \pm S D$ & $\mathbf{T}$ & $\mathbf{P}$ \\
\hline Weight (kg) & Pretest-posttest & $.80 \pm 1.07$ & 4.12 & .00 & $.48 \pm 1.16$ & 2.27 & .03 \\
\hline Duration 2km UKK (min.) & Pretest-posttest & $1.04 \pm .45$ & 12.59 & .00 & $-.56 \pm .40$ & -7.63 & .00 \\
\hline HR (pulse / min) & Pretest-posttest & $8.73 \pm 4.85$ & 9.85 & .00 & $.50 \pm 1.07$ & 2.54 & .01 \\
\hline HR\% & Pretest-posttest & $4.50 \pm 2.49$ & 9.88 & .00 & $.25 \pm .55$ & 2.55 & .01 \\
\hline Distance 2km UKK (km) & Pretest-posttest & $-50 \pm .18$ & -14.58 & .00 & $-0.1 \pm .15$ & -45 & .65 \\
\hline BMI & Pretest-posttest & $.25 \pm .34$ & 4.00 & .00 & $.13 \pm .33$ & 2.23 & .03 \\
\hline Fitness level & Pretest-posttest & $-17.72 \pm 6.02$ & -16.12 & .00 & $-1.07 \pm 3.96$ & -1.48 & .14 \\
\hline $\mathrm{VO}_{2 \max }(\mathrm{ml} / \mathrm{min} / \mathrm{kg})$ & Pretest-posttest & $-7.06 \pm 2.41$ & -16.01 & .00 & $-43.3 \pm 1.55$ & -1.51 & .14 \\
\hline MB (calories) & Pretest-posttest & $11.09 \pm 14.73$ & 4.12 & .00 & $6.64 \pm 15.99$ & 2.27 & .03 \\
\hline$\% \mathrm{H}_{2} \mathrm{O}(\%)$ & Pretest-posttest & $-13.3 \pm 1.33$ & -.54 & .58 & -17.7 .94 & -1.00 & .32 \\
\hline$\%$ Fat (\%) & Pretest-posttest & $.33 \pm 2.53$ & .72 & .47 & $.18 \pm .71$ & 1.43 & .16 \\
\hline
\end{tabular}

$\mathrm{X}$ - mean arithmetic; SD - standard deviation; T - test-t; $\mathrm{P}<0.05$

by test-t calculation (Table 2) revealed a strong statistical significance in the aqua-gymnastics group at the parameters: weight, duration of the test, heart rate, distance, $\mathrm{BMI}, \mathrm{IF}, \mathrm{VO}_{2 \max }$ and basal metabolism parameters and insignificant at the parameters of body water and the amount of fat in the body. In terms of swimming, the analysis of the differences between the two tests reflected statistically significant differences in parameters: weight, duration of $2 \mathrm{~km}$, cardiac / heart rate capacity through HR indicators after effort, \% HR, BMI and MB. After practicing swimming through $2 \mathrm{~km}$ UKK test, there were statistically insignificant differences, for $p<0.05$, at the following parameters: the distance relative to the time, IF, the vital capacity through the indicator $\mathrm{VO}_{2 \max }$, the amount of water and fat in the body. 


\section{Discussions}

Studies on the improvement of cardio-respiratory capacity and of body composition following gymnastics in water have been performed by numerous authors $[12$, 15-18].

Many authors have quantified the results of reducing the cardiac frequency in the aquatic environment between: $17 \mathrm{p} / \mathrm{m}$ while finding that the biological benefits of similar programs, compared to the aquatic environment and the ground have recorded FC values by $13 \%$ lower in the aquatic environment [19-21].

Taking into account the results obtained in numerous studies, it has been agreed by the specialists in the field that $\mathrm{FC}$ effort values in the aquatic environment compared to the values recorded in exercises on the ground should always be reduced by 10,17 beats / minute to work in an optimal area so as to produce the desired effects.

Studies on the dynamics of physiological indicators, VO2max, heart rate, fitness index, on people aged 2026 years old after swimming have been performed by numerous field researchers $[17,22,23,24]$ who found out improvements in the vital and cardiac capacity.

Exercises with portable objects have the role to amplify the effects of general physical development exercises of the body, allowing a more precise control of the movements of the segments and the body as a whole [10].

Determinations of harmony and body composition through IMC, \%fat, \%water in the body, with direct effect on caloric consumption after practicing a physical activity, have been achieved through numerous studies showing positive effects if they are practiced systematically and under the guidance of specialists $[18,25]$.

A study conducted on boys practicing recreational swimming, of relatively equal age to the subjects of our research [23] revealed that the average value of $\mathrm{VO}_{2 m}$ is around $45.59 \pm 9.32 \mathrm{ml} / \mathrm{kg} . \mathrm{min}$, without obtaining a significant progress after testing in consecutive days after practicing the crawl swimming procedure.

Regarding the energy consumption, it was found and it is recognized that it is inferior in water compared to the ground, due to the cardiac frequency, which for the same type of effort is inferior, by the neuromuscular activity of the postural muscles [26, 27].

In recreational aquatic motor activities, according to the existing studies, the higher the number of limbs involved in motion, the more concomitant the body's response to effort is observed [28, 29].

The effort in water gymnastics is aerobic and depends on the objectives and materials used, so the researchers [30-31] noticed that at a heart rate of 110 beats per minute the effort self-perception is quite slight, with a $\mathrm{VO}_{2 \max }$ of $40 \%$, at a value of 130 beats per minute it is hard, $\mathrm{VO}_{2 \mathrm{~m}}$
$50 \%$, at 150 beats / min hard, $\mathrm{VO}_{2 \max } 75 \%$ and above this value the perception is very hard, and the effort is anaerobic, which is not indicated in this type of activity.

According to the Romanian Swimming Federation, six effort zones have been differentiated according to their intensity, the first four zones aiming at speed swimming, performance resistance with predominantly anaerobic and mixed, zone 5 is aimed at intensity effort between $60-85 \%$ and the sixth one refers to the lower aerobic effort zone: It is the area of the compensatory effort, the heart rate is below 120 beats/ min; It has utility in learning and improving the technique, in warming up and post-effort relaxation [32].

A study of the fitness index using the same $2 \mathrm{Km}$ UKK test at Ukrainian students from Physical Education showed a value of 101.89 , an inferior value compared to our students at the initial test, which was 103.87 [22].

The education should be changed. This change is produced under the influence of the pedagogical tradition that of the contemporary word problem and the future being aware that future order to the present [33].

\section{Conclusions}

The results of the research confirm the hypothesis, so values referring to the somatic indexes, the functional motor indexes recorded by the aqua-gymnastics group were superior compared to those in the swimming group.

The functional, motor and somatic effects induced by practicing initiation programs in water gymnastics have significantly higher effects than practicing an initiation program in swimming. Superior results recorded by the students from the physical education and sports program in the framework of this research through the exercise of water gymnastics programs are the result of the specific methodology that allows for a variation of effort and a diversification of the content higher than the one conducted for the initiation programs in swimming.

Gymnastics in water allows for the customization of programs according to the physical level of subjects, and the use of sports materials allows for an efficient and varied effort dosing, contributing to the optimization of the somatic, motor and functional capacity of the practitioners.

We recommend conducting further studies to assess the effects of gymnastics in water on other groups of students through differentiated programs by levels of physical training, age and the use of various sporting materials.

\section{Conflict of interests}

The author declares that there is no conflict of interests. 


\section{References}

1. Badau D. The educational impact of implementation the education through adventure discipline in physical education and sports academic curriculum. Physical education of students, 2017;21(3):108-115. doi:10.15561/20755279.201 7.0302

2. Badau D. Investigational Approaches of the Human Physical Potential, Publisher International Science Culture and Sport Association; 2017. doi:10.13140/RG.2.2.22534.37442

3. Badau D. Sport counseling-a new approach to improve the performances. Annals of Dunarea de Jos University of Galati - Fascicle XV: Physical Education and Sport Management. 2014;1:24-8.

4. Badau D. Ambidextrous in motor activity, Transilvania University Publish House; 2006. (in Romanian)

5. Léger LA, Seliger V, Brassard L. Backward extrapolation of $\mathrm{VO}_{2 \max }$ values from the $\mathrm{O}_{2}$ recovery curve. Med Sci Sports Exerc. 1980;12:24-27.

6. Montpetit RR, Léger LA, Lavoie JM, Cazorla G. $\mathrm{VO}_{2}$ peak during free swimming using the backward extrapolation of the O2 recovery curve. Eur J Appl Physiology. 1981;47:38591

7. Zamparo P, Lazzer S, Antoniazzi C, Cedolin S, Avon $\mathrm{R}$, Lesa $\mathrm{C}$. The interplay between propelling efficiency, hydrodynamic position and energy cost of 583 front crawl in 8 to 19 year-old swimmers. European Journal of Applied Physiology. 2008;104(4):689-99. doi:10.1007/s00421-0080822-7

8. Zamparo P, Swaine IL. Mechanical and propelling efficiency in swimming derived from exercise using a laboratory-based whole-body swimming ergometer. Journal Applied Physiology. 2012;113:584-94. doi:10.1152/ japplphysiol.00324.2012.

9. Chaverri D, Iglesias X, Schuller T, Hoffmann U, Rodríguez F. Estimating peak oxygen uptake based on postexercise measurements in swimming. Appl Physiol Nutr Metab. 2016;41(6):588-96. doi:10.1139/apnm-2015-0524.

10.Badau A, Badau D. Aqua-pullpush-gym. An novative method of gymnastic in water. Transilvania University Publish House; 2011.

11. Toskić D, Lilić L, Milenković V, Toskić. Comparative analysis of different curricula on students' swimming techniquesac quisition. Research in Kinesiology. 2014;42(2):96-99.

12.Statkevičienè B, Venckūnas T. Athletes' anthropometrical measurements and physical capacity influence on learning competitive swimming techniques. Acta Medica Lituanica. 2008;15(4):229-34.

13.Mendez Resende S. New protocol of hydrotherapy in the recovery of balance and prevention of falls in elderly $[\mathrm{PhD}$ thesis]. Catholic University Goiás; 2007. [cited 2017 Apr 24]. Available from:http://tede2.pucgoias.edu.br:8080/ bitstream/tede/3060/1/Selma\%20Mendes\%20Resende.pdf (In Portuguese)

14.Kudryavtsev MD, Kopylov YA, Kuzmin VA, Ionova OM, Yermakova TS. Personality oriented system of strengthening of students' physical, psychic and socialmoral health. Physical education of students. 2016;3:43-52. doi: 10.15561/20755279.2016.0308

15.Takeshima N, Rogers ME, Watanabe WF, Brechue WF, Okada A, Yamada T, Islam MM, Hayano J. Water - Based exercise improves health - related aspects of fitness in older women. Med. Sci. Sports Exerc. 2002;33(3):544-51.

16.Badau D, Prebeg G, Mitić D, Badau A. Fitness index and $\mathrm{VO}_{2 \max }$ of physical education students, Ovidius University Annals, Series Physical Education and Sport, Science,
Movement and Health. 2015;15(2 Supplement):246-51.

17. Costa $\mathrm{AV}$, Costa MC, Gomes JLB, Guimarães FJSP, Barbosa TM. Applicability of an indirect $\mathrm{VO}_{2 \max }$ Test: its association with the 400 meters freestyle performance. Motriz: Revista de Educação Física. 2016;22(4):304-9. doi:10.1590/S1980-6574201600040014

18. Mehrzad S, Saeid S, Rouholah F. Study of body mass index (BMI), body fat percent (\%bf), and waist to hip ratio (WHR) in male physical education students. Physical education of students. 2015;3:74-78. doi:10.15561/20755279.2015.0309.

19. Windhorst MY, Chossek V. Aquatic exercise association manual. Port Washington, WI: Aquatic exercise association; 1988.

20.Lindle J. Water exercise research. AKWA, 1989;3(4):11-3.

21.Colado JC, Moreno JA. Fitness acuatico. INDE Publicaciones: Zaragoza; 2001.

22.Pavlović R. Evaluation of fitness index and maximal oxygen consumption of students using the UKK $2 \mathrm{~km}$ walk test. Journal of Physical Education and Sport. 2016;16(1):26974. doi:10.7752/jpes.2016.01043

23.Clemente-Suárez VJ, Dalamitros A, Ribeiro J, Sousa A, Fernandes RJ, Vilas-Boas JP. The effects of two different swimming training periodization on physiological parameters at various exercise intensities. Eur J Sport Sci. 2017;17(4):425-32. doi:10.1080/17461391.2016.1253775

24.Kyselovičová O, Labudová L, Zemková E, Čierna D, Jeleň M. Anthropometric and cardiovascular variables of elite athletes. Acta Facultatis Educationis Physicae Universitatis Comenianae. 2016;56(2):143-58. doi:10.1515/ afepuc-2016-0012

25.Petrenko N, Loza TA. Model of recreational and training sessions based on the use of funds aqua professionally applied in the preparation of students of economics. Physical Education of Students. 2014;18(4):32-6. doi:10.6084/ m9.figshare.974481.v1

26.Borg G, Hassmen P, Lagertrom M. Perceived exertion related to heart rate and blood lactate during arm and leg exercise. Eur J Appl Physiol Occup Physiol. 1987;56(6):679-85.

27.Bouchard C, Shephard E. Physical Activity, Fitness and Health. International Preceeding and Consensus Statement. Champaing: Human Kinetics Publisheres; 1994.

28.Darby LA, Yaeckle BC. Physiological responses during two types of exercise performed on land and in water. $J$ Sports Med Phys Fitness. 2000;40(4):303-11.

29.Barbosa TM, Marinho DA, Reis VM, Silva AJ, Bragada JA. Physiological Assessment of Head-Out Aquatic Exercises in Healthy Subjects: A Qualitative Review. Journal of Sports Science \& Medicine. 2009;8(2):179-189.

30.Colado JC, Borreani S, Pinto SS, Tella V, Martin F, Flandez J, Kruel LF. Neuromuscular Responses During Aquatic Resistance Exercise With Different Devices and Depths, J Strength Cond Res. 2013;27(12):3384-90. doi:10.1519/ JSC.0b013e3182915ebe

31.Borg G. Perceived Exertion and Pain Scales. Champaign, IL: Human Kinetics Publishers; 1998.

32.Marinescu G. Children and performance in swimming, Publishing by Romanian Federation of Swimming: Bucharest; 1998. (in Romanian)

33.Ion-Ene M, Neofit A. The early education in the educational new context, Universitaria. 2016;18:54-9. 


\section{Information about the author:}

Badau Adela; http://orcid.org/0000-0002-1656-5060; adela.badau@umftgm.ro; Department of Physical Education, Faculty of Medicine, University of Medicine and Pharmacy of Targu Mures; Strada Gheorghe Marinescu 38, Târgu Mureș 540139, Romania.

Cite this article as: Badau Adela. Study of somatic, motor and functional effects of practicing initiation programs in water gymnastics and swimming by students of physical education and sports. Physical education of students, 2017;21(4):158-164. doi:10.15561/20755279.2017.0402

The electronic version of this article is the complete one and can be found online at: http://www.sportedu.org.ua/index.php/PES/issue/archive

This is an Open Access article distributed under the terms of the Creative Commons Attribution License, which permits unrestricted use, distribution, and reproduction in any medium, provided the original work is properly cited (http://creativecommons.org/licenses/by/4.0/deed.en).

Received: 22.05.2017

Accepted: 10.06.2017; Published: 10.08 .2017 